Session 2148

\title{
Promoting Flexible Teaching: Implications for Faculty and Administrators
}

\author{
Stephen P. Hundley, Patricia L. Fox \\ Indiana University Purdue University Indianapolis
}

\section{Introduction}

Many learners - especially adult and commuter students - often cite time, money, childcare responsibilities, work schedules, and transportation difficulties as barriers to their sustained participation in postsecondary education. Yet many institutions still schedule courses using an outdated, agrarian-based calendar that stretches courses over 15+ weeks. As retention and persistence issues continue to be of paramount importance in higher education, faculty and administrators must work in tandem to create alternative ways for students to take courses that allow them to complete their credentials in a faster manner.

This paper highlights the challenges and rewards of teaching courses in concentrated formats, and answers the following questions: (a) Why teach in concentrated formats? (b) Which courses are candidates for concentrated formats? (c) What strategies ensure quality in concentrated formats? and (d) How can institutions begin offering courses in concentrated formats? Faculty interested in adapting their courses to concentrated formats will find the experiences and insights the paper offers extremely helpful, while administrators will learn how to support faculty in their quest to offer courses in these formats.

\section{Why Teach in Concentrated Formats?}

The Department of Organizational Leadership and Supervision (OLS) in the Purdue School of Engineering and Technology at Indiana University Purdue University Indianapolis (IUPUI) regularly offers case- and project-based courses in one-week intensive formats. These courses are highly experiential, and require that students prepare in advance for the intense class, usually through pre-work reading assignments. Additionally, several post-class assignments are required, and students submit their work several weeks after the class-meeting period concludes. Therefore, while the contact-hours related to the teaching-learning process is only one week in duration, the entire context of learner involvement - pre-work, class meeting time, and post-work - usually spans over several months.

There are a number of reasons why courses can and should be offered in concentrated formats. First, and perhaps most significantly, is student demand. At our urban, commuter-oriented public institution, the mean age for students is 28 . Many are part-time, returning, and/or delayed-entrant students, who must balance the demands of school with work, family, and other outside responsibilities. As a result, our students are interested in taking courses in formats that 
are respectful of their time constraints, and that meet at times when it is convenient for them to take classes.

Retention and persistence are also compelling reasons for teaching courses in concentrated formats. Most institutions - especially public colleges and universities - operate in an environment increasingly evaluated by performance indicators. The ability to retain students in degree programs is challenging, given the marked increase in postsecondary education competition from both traditional providers and new entrants. Moving beyond the historic, agrarian-based academic calendar is a must if institutions are to be competitive in attracting and retaining students. In addition, offering courses in concentrated formats potentially facilitates persistence toward degree completion at a much faster rate than would normally be possible by using the traditional academic calendar for all courses.

For certain courses, teaching them in concentrated formats makes sense from a pedagogic standpoint. Total, focused, intense immersion for a shorter period of time, rather than fragmented, interrupted learning that spans the length of a semester, may be preferred for courses emphasizing the case study or problem-based learning approach. The concentrated format allows for students to focus exclusively on the content of a single course, rather than creating a "learning hierarchy" that is almost necessary when a student attempts to take multiple classes in one semester.

Courses taught in concentrated formats also have the potential to utilize institutional resources during otherwise idle times. At our institution, for example, we teach courses the week between Christmas and New Year's, as well as during the Spring Break week. From the teaching standpoint, having access to numerous classrooms for group breakout sessions is a luxury an instructor would not normally enjoy during the regular semester. From the institution's standpoint, we are generating credit hour revenue that would normally not be earned. And from the student's standpoint, they are able to take a concentrated course that does not interfere with their ability to also take traditionally scheduled classes.

Finally, concentrated format courses are a nice fit for classes employing distance-learning technologies. By equipping students with the knowledge, resources, and materials to be selfdirected learners via the Internet, concentrated course meetings can augment the information covered online by providing a face-to-face classroom experience. This is especially important for courses requiring the dynamics of human interaction that, at present, cannot be fully simulated in a web-based environment.

\section{Which Courses are Candidates for Concentrated Formats?}

Let's begin with a caveat: not all courses can or should be concentrated. There are many courses, mathematics and literature for example, that would face numerous challenges in having a student attempt to master the subject matter in a short period of time. Therefore, courses requiring recitation and complex skill-building that can only be mastered by learning, practicing, reflecting, and improving over a multiple week/month period are not likely candidates for concentrated formats. 
Courses that emphasize experiential, problem-based, and case study learning, for which there are either no prerequisites or for which the learner possesses the prerequisite knowledge, are excellent candidates for concentrated format offerings. Essentially, any course is a candidate for this format if it can be designed to permit students to (a) complete a portion of the work on an independent basis in advance; (b) meet for an intense period of classroom instruction and interaction; and (c) complete a portion of the work on an independent basis after the class has met.

An instructor's teaching style is also an important consideration in selecting what type of course to teach in a concentrated format. There is an old saying that goes, "the mind cannot absorb any more than the seat can endure." Never has this been truer than for courses meeting all day long for five days in a row! Instructors who are prone to use lecturing as their preferred pedagogic technique are likely to face burnout themselves, not to mention overwhelming their students, during a concentrated course. Therefore, courses that blend a variety of pedagogic approaches, such as lectures, group work, guided discussions, role playing, games/simulations, videos, and guest speakers, are likely to be met with success in this type of format.

\section{What Strategies Ensure Quality in Concentrated Formats?}

One of the biggest cries we heard from faculty who were dubious of any course that could be taught in a concentrated format was, "...but how will you ensure quality?" This question is valid, not only for concentrated courses, but, indeed, for every course taught, including traditional semester-length courses. There are several strategies that can be employed to monitor and improve quality in concentrated courses. By far, the most obvious method for ensuring quality is to carefully select which course(s) will be taught in a concentrated format. Having a clear rationale (i.e. student demand) and a valid pedagogic response (i.e. concentrated formats work well for case-study teaching) ensures that courses selected for this format will be chosen with care and emphasis on student learning.

In addition to appropriately selecting courses, explicitly documenting the course expectations and objectives, and communicating them to students in advance, can serve to ensure a quality learning experience. To what extent must pre-work be completed in advance of the concentrated course meeting times? What is the attendance policy for concentrated courses? What types of post-class assignments must students complete? How long will students have to submit their work? Will you allow the use of outside resources (i.e. readings and Internet/WWW) in completing the assignments? These questions are representative of the type of information that must be decided upon by the instructor and conveyed to students upon their registration for the course.

The use of peer review of teaching is also encouraged. In the Labor Relations class, described above, an adjunct instructor with considerable industry experience observed the concentrated, 1week course, and provided evaluative feedback that served to both validate the teaching method and improve on the course design and delivery.

Finally, and perhaps most importantly, is the use of well-timed student feedback. Assessing the learner's needs before the class meets - and again on the first day of the class meeting - ensures 
that the instructor matches activities to the level of preparedness of the student. Feedback is also essential during the concentrated learning course itself, whether it be informal end-of-day-type feedback, or a more explicit assessment of the learner's knowledge, such as a quiz or examination. Post-class assignments are also an important feedback mechanism, especially as it relates to the student's ability to reflect upon the course material after the class meeting time has concluded.

\section{How Can Institutions Begin Offering Courses in Concentrated Formats?}

Literally every institution of higher education has the opportunity to experiment with offering some of its courses in concentrated formats. After determining the viability of teaching a particular course in a concentrated format, one of the first steps a faculty member must take is to conduct market research with prospective students. Determining the extent to which sufficient interest exists in this format can be done via interviews, informal feedback during student advising sessions, surveys, focus groups, etc.

Once the faculty determine that there are students who would take a course in a concentrated format, securing senior administration's support for this effort is next. By making the arguments outlined earlier in this paper, coupled with the information obtained from the institution-specific market research, most administrators should see (we hope!) the benefits of offering a concentrated course. At the very least, attempt to secure support to pilot-test the offering of a course in this format, with the idea that the course will be fully evaluated in terms of the teaching-learning processes and student outcomes.

From a pragmatic standpoint, faculty offering concentrated courses will want to ensure that the institutional infrastructure can support the course schedule and structure. When we offered our initial course between Christmas and New Year's, for example, we failed to realize that computing resources would be unavailable to our students, since the computing services departments were closed for the holidays. In subsequent holiday concentrated formats, we have rectified this, but initially we simply overlooked the potential use of computers and Internet access for components of the case study assignments during our courses.

Faculty implementing concentrated courses - especially those offered during times when the institution will otherwise be idle - will want to consider the following: What semester the course should be tied (for our holiday course, it was considered a spring semester course that simply met early). What will be the faculty compensation (will there be an overload payment, or will it count toward the regular teaching load)? What special campus resources (library, technology, laboratory, etc.) are needed for the course, and to what extent will they be available? Involving the campus's registrar's, computing services, and physical plant offices in the planning of the concentrated courses can go a long way toward minimizing mishaps during the teaching of the course.

As faculty prepare to launch their course in a concentrated format, they need to determine how student learning will be assessed. Given that the concentrated nature of the course may make it more challenging to have a traditional examination to test students' learning, alternative methods of assessing learning must occur. In our courses, we have found it useful to assign relevant pre- 
work, including readings and short papers. During the concentrated course, we do not assign work to be completed during the time the course meets, since the lengthy days and concentrated meeting times (i.e. one week) make it burdensome to assign a lot of work each night. Instead, we have assignments, usually in the form of take-home tests, papers, projects, etc., that permit the student to work independently, reflect and synthesize their learning, and submit the work several weeks after the last class meeting.

One of the biggest differences between teaching courses in concentrated formats vs. teaching them in traditional semesters is the lack of "down time" for instructors and students in between each class meeting. If something clearly isn't working in a traditional semester, faculty have natural pauses between each class period to reassess and redesign their approach, if necessary. In the concentrated format, however, faculty have to be much more attuned to redesigning their course on-the-spot if something (a lecture, group activity, etc.) clearly isn't working. Therefore, being comfortable with ambiguity, experimentation, and risk taking are important attributes and skills necessary to maintain the flexibility required in teaching courses in this format.

Finally, and perhaps most saliently, faculty have to prepare themselves mentally and physically for teaching the course in a unique way. Two pragmatic pieces of advice: get plenty of sleep the night before the first class (trust us, you will need it!), and always, always plan a highly experiential activity immediately after lunch - this is the time students are most prone to nod off, so a less-than-stimulating lecture or darkening a room to view a videotape are not prudent instructional choices at this point during the day.

\section{STEPHEN P. HUNDLEY}

Stephen P. Hundley is Assistant Professor of Organizational Leadership and Supervision in the Purdue School of Engineering and Technology at Indiana University Purdue University Indianapolis (IUPUI), where he teaches human resources management, labor relations, and strategic compensation. He regularly speaks on higher education and human resources issues to a variety of audiences, and he is the author of two forthcoming books: Internal Consulting in Higher Education Human Resource Management (College and University Personnel Association, 1999) and A Leader's Guide to Understanding Organizations (Sage Publications, 2000). Stephen has taught a number of concentrated format courses at IUPUI. Finally, he holds a Ph.D. from American University, and is certified by the Society for Human Resource Management as a Senior Professional in Human Resources.

\section{PATRICIA L. FOX}

Patricia L. Fox is the Assistant Dean for Administration and Finance and Assistant Professor of Organizational Leadership and Supervision in the Purdue School of Engineering and Technology at Indiana University Purdue University Indianapolis (IUPUI). Pat is currently serving as the Engineering Technology Division's (ETD) Program Chair for the 2001 ASEE national conference. She also serves as a Director on the Engineering Technology Council (ETC). Pat has taught several concentrated format courses at IUPUI. Pat holds a MBA from Butler University. 